\title{
Assessment of age changes and repeatability for computer-based rod dark adaptation
}

\author{
Laura Patryas • Neil R. A. Parry • David Carden • \\ Daniel H. Baker • Jeremiah M. F. Kelly • Tariq Aslam • \\ Ian J. Murray
}

Received: 22 November 2012 /Revised: 7 March 2013 /Accepted: 12 March 2013 / Published online: 5 April 2013

(C) The Author(s) 2013. This article is published with open access at Springerlink.com

\begin{abstract}
Purpose To characterize the rate of rod-mediated sensitivity decline with age using a PC-driven cathode ray tube (CRT) monitor. To provide data regarding the repeatability of the technique.

Methods Dark adaptation was monitored for 30 min following a minimum $30 \%$ pigment bleach, using a white $1^{\circ}$ stimulus (modulated at $1 \mathrm{~Hz}$ ), presented $11^{\circ}$ below fixation on a CRT monitor. Thirty-three subjects with no ocular pathology and normal fundus photographs were divided into two groups: older $(\geq 45, n=16)$ and younger $(<45, n=17)$.

Results Rod recovery was assessed using component S2 of dark adaptation. S2 was significantly slower in the older $\left(0.19 \pm 0.03 \mathrm{log} \mathrm{cd} \cdot \mathrm{m}^{-2} \cdot \mathrm{min}^{-1}\right)$ compared with the younger group $\left(0.23 \pm 0.03 \log \mathrm{cd} . \mathrm{m}^{-2} \cdot \mathrm{min}^{-1}, t=-4.05, p<0.0003\right)$, despite no difference in visual acuity and fundus appearance. Faster rates of S2 recovery were correlated with lower threshold at $30 \mathrm{~min}\left(\mathrm{~T}_{30}\right)(r=-0.49)$. Correlation coefficients between first and second measurements for S2 and $\mathrm{T}_{30}$ were $0.49(p<0.009)$ and $0.84(p<0.0001)$ respectively. The coefficient of repeatability was $0.07 \mathrm{log} \mathrm{cd} \cdot \mathrm{m}^{-2} \cdot \mathrm{min}^{-1}$
\end{abstract}

L. Patryas $(\bowtie) \cdot$ D. Carden · J. M. F. Kelly $\cdot$ I. J. Murray

The Vision Centre, Carys Bannister Building, Faculty of Life

Sciences, University of Manchester, Manchester M13 9PL, UK

e-mail: laura.patryas@manchester.ac.uk

N. R. A. Parry $\cdot$ T. Aslam

Vision Science Centre, Manchester Royal Eye Hospital,

Manchester, UK

N. R. A. Parry $\cdot$ T. Aslam

University of Manchester Academic Health Science Centre,

Manchester, UK

D. H. Baker

Department of Psychology, University of York, York, UK for $\mathrm{S} 2$ and $0.35 \log$ cd.m $\mathrm{m}^{-2}$ for $\mathrm{T}_{30}$. The coefficients of variation for $\mathrm{S} 2$ and $\mathrm{T}_{30}$ were $15 \%$ and $10 \%$ respectively. Conclusions Dark adaptation is slowed in normal ageing. CRT-based dark adaptometry is easily implemented and highly repeatable. The technique described in this article would be useful for documenting visual changes in future clinical trials assessing retinal health in the older eye with and without ocular pathology.

Keywords CRT · Dark adaptometry · Rods · Ageing · Repeatability

\section{Introduction}

Dark adaptometry is considered a useful tool for investigating a variety of systemic and ocular diseases including vitamin A deficiency [1], liver disease [2], diabetes [3, 4], age-related macular degeneration (AMD) [5-10], retinitis pigmentosa [11] and congenital stationary night blindness [12]. It has also been used to assess non-pathological mechanisms of ageing $[13,14]$. The term 'dark adaptation' refers to the gradual recovery of visual sensitivity in total darkness following exposure to a bright light. The light bleaches the photoreceptor visual pigment, resulting in its inactivation and a profound ( $\sim 5 \log$ units) loss of sensitivity. Classically, the dark adaptation function has been described as biphasic, and comprises an initial rapid phase subserved by the cones, followed by a slower phase subserved by the rods. In recent years, significant advances have been made in our understanding of the biological processes underpinning rod recovery [15]. In terms of analysing and modelling dark adaptation data to obtain clinically useful parameters, the rod recovery can be partitioned into three partly overlapping components: S1, S2, and S3 [16]. Normally, S1 is obscured 
by cone recovery so that, in the standard dark adaptation curve, $\mathrm{S} 2$ is the first measurable sign of rod recovery.

Slowed dark adaptation, particularly the rate of $\mathrm{S} 2$, is characteristic of ageing and AMD, and precedes retinal changes and cone-mediated visual function changes such as reduced visual acuity (VA) $[8,9,14,17,18]$. Dark adaptometry is, therefore, likely to become the test of choice for investigating ageing and assessing efficacy of therapies and management strategies for early stage AMD. To that end, an inexpensive, readily available and repeatable technique for measuring dark adaptation kinetics will be essential if functional, as well as structural, features form part of the clinical outcomes.

There have been many studies aimed at using dark adaptation to assess age-related ocular pathology, but few have provided data regarding the repeatability of the slope of S2. Accurate determination of this parameter's repeatability is important, because detecting small changes in the slope of $\mathrm{S} 2$ is of clinical significance. The problem of accurate determination of dark adaptation parameters is compounded by the fact that data obtained from elderly subjects, who may or may not have ocular pathology, are usually more variable than those produced by young, healthy individuals. Repeatability and reliability of any technique will, therefore, be paramount to its applicability.

Two recent studies employed cathode ray tube (CRT) technology to assess dark adaptation kinetics $[18,19]$. CRTs are ideally suited to, and used extensively in, visual psychophysics research. Their temporal and spatial characteristics are well-documented, and they are easily controlled by a computer. A major limitation of using computer monitors for dark adaptation, however, is that they have a limited dynamic range, but this problem can be avoided by the use of neutral density (ND) filters [18].

As far as we are aware, the coefficient of repeatability (CoR) for the rod parameters measured by CRT dark adaptometry has not yet been established. The CoR is important when evaluating the performance of an instrument that is used to detect clinically significant changes over the course of an intervention trial [20]. In this study, we use a customized version of commercially available software to investigate the ability of CRT-based dark adaptometry to quantify delays in rod-mediated recovery in ageing. We also provide data regarding the repeatability of this technique.

We chose to focus on the measurement of the slope of S2, since rods are more vulnerable than cones in ageing and AMD [8, 9, 21].

\section{Methods}

\section{Subjects}

Thirty-three normal volunteers participated in this study, and were divided into two groups. The older group
( $\geq 45$ years old, age range $45-68$, mean $57.44 \pm 7.98, n=16$ ) consisted of eight males and eight females. The younger group ( $<45$ years old, age range $15-36$, mean $25.12 \pm 6.08$ $n=17$ ) consisted of ten males and seven females.

Younger subjects were primarily recruited from the University of Manchester undergraduate population and older subjects from university staff. Informed consent was obtained. The tenets of the Declaration of Helsinki were followed. This study was approved by the University of Manchester Committee on the Ethics of Research on Human Beings.

All subjects had recently had an eye examination (up to 12 months before recruitment), were free from any ocular disease (e.g., glaucoma, AMD, cataract) and were not taking nutritional supplements. Subjects with diabetes or liver disease, current smokers, and those using systemic medications known to be retinotoxic were excluded from the study.

On the day of testing, all subjects underwent assessment of VA and dark adaptation. Fundus photographs were taken with a TRC-NW6S Non-Mydriatic Retinal Camera (Topcon, Tokyo, Japan). The VA was measured using an internally illuminated Early Treatment of Diabetic Retinopathy Study

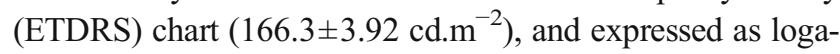
rithm of the minimum angle of resolution (logMAR).

The fundus photographs were processed using IMAGE Net 2000 software (Topcon, Tokyo, Japan) and viewed on a 20 -in . monitor $(1,600 \times 1,200$ pixels, 32 bits). The fundus images of all participants were graded by one of the authors (LP) according to a macular grading scale [14]. No subject had a grade beyond 1 , thus all were classified as being normal.

\section{Procedure}

The stimuli were generated using a visual stimulus generator (VSG 2/5, Cambridge Research Systems, Rochester, UK) running Visual Psychophysics Engine software (Cambridge Research Systems, customized by NRAP) and presented on a calibrated and gamma-corrected high-resolution CRT monitor (Sony GDM-F500R, Tokyo, Japan). A black cardboard mask with four apertures corresponding to the stimuli and fixation cross was placed over the monitor screen. One or more $1.2 \log$ unit ND filters (\#299; Lee Filters, Andover, UK) were placed in front of the test stimulus in the configuration illustrated in Fig. 1.

The observer fixated a red cross $\left(0.3^{\circ}\right)$ at position 1 , and responded to a $1^{\circ}$ circular test spot (1931 CIE $x=0.31, y=$ 0.316 ), temporally modulated with a $1 \mathrm{~Hz}$ square wave and presented at $11^{\circ}$ in the inferior field (a location typically used in the standard Goldmann-Weekers adaptometer). The stimulus intensity was attenuated by a $1.2 \log$ unit ND filter that extended over both stimulus locations. When the absolute filtered intensity of the stimulus was below $-2.3 \log \mathrm{cd} . \mathrm{m}^{-2}$ (usually after about $12-15 \mathrm{~min}$ ), the fixation cross and stimulus at position 1 were extinguished and re-appeared in 




Fig. 1 The experimental set up. A mask with four apertures corresponding to the stimuli and fixation cross locations covered the entire screen. A $1.2 \log$ unit ND filter was attached to the back of the mask at stimulus positions 1 and 2 . When the filtered screen luminance fell below $-2.3 \log \mathrm{cd} . \mathrm{m}^{-2}$, the fixation cross and the stimulus were extinguished at position 1 and moved to position 2, where an additional smaller $2.4 \log$ unit ND filter (attached to the back of the mask) exposed the remaining region of rod recovery. The retinal area to be tested was accurately bleached by aligning the flash with the stimulus (at position 1) through the use of a semi-silvered mirror

position 2. At this location, the stimulus was further attenuated by a $2.4 \log$ unit ND filter, so that total attenuation for the latter stages of the procedure was $3.6 \log$ units. The dynamic range was sufficient (approximately $5.5 \mathrm{log}$ units) to enable the measurement of the entire scotopic recovery function. A similar approach has been used previously with the filters mounted on goggles worn by the observer $[18,19]$. In our procedure, the expansion of the dynamic range by addition of further ND filters is fully automatic. In the absence of other visual cues (as the subject is in total darkness), the shift in location of the targets is rarely noticed.

All subjects were dark-adapted for $5 \mathrm{~min}$, followed by a practice session for a further $5 \mathrm{~min}$. A localised 30-98\% visual pigment bleach [22] was then performed using an electronic $0.9 \mathrm{~ms}$ flash of white light (Nikon Speedlight SB800, Tokyo, Japan). The flash intensity was $6.08 \mathrm{log}$ cd.s.m ${ }^{-2}$, as measured using a PR1500 spot photometer (Photo Research, Burbank, CA, USA). Since the rate of S2 is independent of the bleach magnitude provided the bleach is greater than 10-20\% [15], we performed the measurements on natural pupils.

The flashgun was positioned $15 \mathrm{~cm}$ from the eye, and at this distance subtended an angle of $20.9^{\circ}$ wide by $13.3^{\circ}$ high. The flash and the bleach area were precisely aligned so that location of the test stimulus was centred on the bleached area of the retina. This was achieved by using a calibrated semi-silvered mirror, as illustrated in Fig. 1, so that the subject observed the fixation mark when the flash was fired. An adjustment of $0.3 \log$ units was made to all thresholds to compensate for the absorption characteristics of the mirror, which remained in place throughout the experiment.

Monocular thresholds were measured in complete darkness in a purpose-built room immediately after bleaching. The experiment was controlled by a computer external to the dark room. Stimulus luminance was reduced in steps of 0.1 $\log$ unit until the subject reported its absence. Thresholds were set approximately twice per minute for a duration of $30 \mathrm{~min}$. The non-stimulated eye was patched during testing, and the subjects wore their best optical correction for the test distance. The subject's head was positioned in a chin/head rest. All participants repeated the dark adaptation measurement twice, separated by at least 1 week. The data presented hereafter are the means of two visits.

\section{Data analysis}

Dark adaptation curves were plotted as $\log _{10}$ threshold in cd. $\mathrm{m}^{-2}$ versus time in minutes. These were fitted with a single exponential component to the cone phase and two linear components to the rod phase, as described by McGwin et al. [23]. The non-linear regression technique was implemented in Matlab (Mathworks, MA, USA) and yielded the following parameters of the dark adaptation curve: cone recovery rate, cone threshold, the rod-cone break (RCB), the slopes of the second (S2) and third (S3) rod components, the transition point between the two, and the threshold $30 \mathrm{~min}$ after the bleach $\left(T_{30}\right)$. Of these parameters, we were primarily interested in component $\mathrm{S} 2$ and $\mathrm{T}_{30}$. The latter was corrected for preretinal absorption (pupil diameter and media opacity) based on previous work [24-27].

Kolmogorov-Smirnov tests were used to determine that the distributions of all dark adaptation parameters did not differ from normal. Origin ${ }^{\circledR}$ (Northampton, MA, USA) and Matlab were used for statistical analysis and graph plotting. Repeatability was assessed using the standard correlation coefficient (Pearson's $r$ ) and by calculating the CoR (1.96 multiplied by the standard deviation of the differences between test and retest data) and coefficients of variation $(\mathrm{CoV}$, the ratio of the standard deviation to the mean multiplied by 100). Independent sample $t$-tests were used to make comparisons between groups (younger vs older, males vs females).

\section{Results}

Preliminary data

Figure 2a depicts a classic dark adaptation function obtained with our CRT-based technique for a young, healthy observer (LP, one of the authors). An exponential-bilinear model partitioned the curve into three distinct phases of sensitivity 

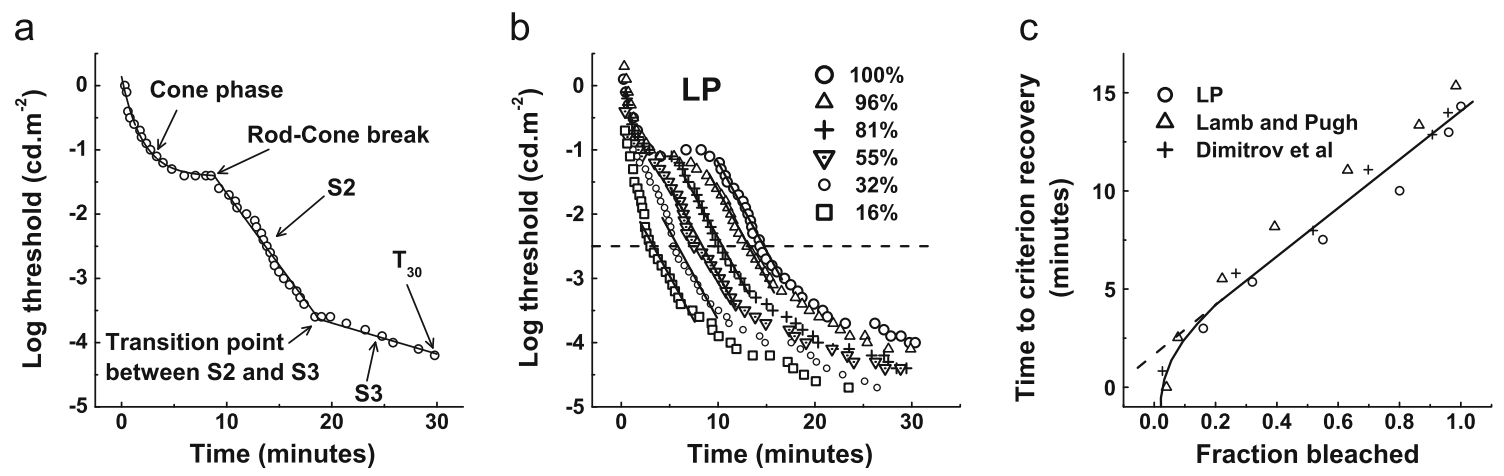

Fig. 2 a Typical dark adaptation data measured with our CRT-based technique for a young, healthy observer (LP) measured inferiorly at $11^{\circ}$ degrees eccentricity, using a $1^{\circ}$ white light stimulus following an $82 \%$ bleach. The data points were fitted with an exponential-bilinear model. $S 2$ is the second rod component, $S 3$ is the third rod component and $T_{30}$ is the threshold $30 \mathrm{~min}$ after the bleach. SSE $=0.3, r^{2}=0.9$. b Dark adaptation curves for the same observer using the same technique

recovery: a cone-mediated phase, followed by a rodmediated phase divided into two linear regions. The two components of rod dark adaptation, S2 and S3, had negative slopes of $0.24 \mathrm{log} \mathrm{cd} \cdot \mathrm{m}^{-2} \cdot \mathrm{min}^{-1}$ and 0.06 $\log \mathrm{cd} \cdot \mathrm{m}^{-2} \cdot \mathrm{min}^{-1}$ respectively.

The parallel lines in Fig. $2 \mathrm{~b}$ plot component $\mathrm{S} 2$ for different bleach intensities. There was no significant correlation between bleach and slope of S2 $(r=0.65, p>0.23)$, confirming that this phase of rod recovery is independent of the bleach magnitude provided that the bleach is greater than 10-20\%. In Fig. 2c, the time taken to reach an arbitrary threshold of $-2.5 \log$ units (extracted from Fig. 2b) was re-plotted against the fraction bleached. The straight line fit when plotted in semi-logarithmic co-ordinates for bleaches greater than 10 $20 \%$ reveals the rate-limited behaviour of S2.

\section{Repeatability}

In order to quantify measurement error, repeated measurements were obtained on different days. The final three columns of Table 1 summarize correlation coefficients, CoRs, and COVs for the following parameters: $\mathrm{RCB}, \mathrm{S} 2, \mathrm{~S} 3$, and $\mathrm{T}_{30}$. Of these, we were primarily following a range of bleaches (16-100\%). The parallel solid lines plot component S2 and demonstrate a constant rate of rod recovery across bleaches. The horizontal dashed line is an arbitrary criterion ( $-2.5 \log$ units) used to plot the graph in panel c. c Linear relationship between fraction bleached (above $20 \%$ ) and the time required to reach a criterion recovery level for our data (LP) and those from previous studies

interested in $\mathrm{S} 2$ and $\mathrm{T}_{30}$. Correlation coefficients between first and second measurements for $\mathrm{S} 2$ and $\mathrm{T}_{30}$ were $0.49(p<0.009)$ and $0.84(p<0.0001)$ respectively. The average absolute change between sessions (dotted line in Fig. 3) was $0.004( \pm 0.04) \log \mathrm{cd} \cdot \mathrm{m}^{-2} \cdot \mathrm{min}^{-1}$ for $\mathrm{S} 2$ and $0.05( \pm 0.23) \log {\mathrm{cd} . \mathrm{m}^{-2}}$ for $\mathrm{T}_{30}$, indicating only minimal bias. The CoR was $0.07 \log \mathrm{cd} \cdot \mathrm{m}^{-2} \cdot \mathrm{min}^{-1}$ for $\mathrm{S} 2$ and $0.35 \log \mathrm{cd} . \mathrm{m}^{-2}$ for $\mathrm{T}_{30}$. The $\mathrm{CoV}$ was $15 \%$ for $\mathrm{S} 2$ and $10 \%$ for $\mathrm{T}_{30}$.

\section{Dark adaptation in older and younger eyes}

VA in the test eye for all subjects was at least $0.2 \log$ MAR, and there was no difference in VA between the two groups $(t=1.00, p=0.3)$. Figure 4 depicts rod dark adaptation kinetics (components S2 and S3), after the RCB, for the younger and the older group. Each subject's curve was linearly shifted in $x$ and $y$ directions, so that their individual RCBs were coincident. The group data were fitted with a bilinear function. The older group (solid line, Fig. 4b) had a shallower slope of S2 compared with the younger group (dashed line), indicating slower rate of recovery. The vertical (upward) shift in the older group along the $y$-axis

Table 1 Summary of statistical comparisons: older vs younger group and test-retest repeatability

\begin{tabular}{|c|c|c|c|c|c|c|}
\hline Parameter & $\begin{array}{l}\text { Older group mean } \\
( \pm \mathrm{SD})\end{array}$ & $\begin{array}{l}\text { Younger group mean } \\
( \pm \text { SD })\end{array}$ & $P$ value $^{\mathrm{a}}$ & $\begin{array}{l}\text { Test-retest correlation } \\
\text { coefficient, }(p \text { value })\end{array}$ & $\begin{array}{l}\text { Test-retest } \\
\text { CoR }\end{array}$ & $\begin{array}{l}\text { Test-retest } \\
\text { CoV }\end{array}$ \\
\hline RCB (mins) & $7.20(2.45)$ & $7.04(1.53)$ & 0.82 & $0.67(<0.0001)$ & 3.62 & $28 \%$ \\
\hline $\begin{array}{l}\text { S2 }(\log \\
\left.\text { cd. } \mathrm{m}^{-2} \cdot \min ^{-1}\right)\end{array}$ & $0.19(0.03)$ & $0.23(0.03)$ & $<0.0003$ & $0.49(<0.009)$ & 0.07 & $15 \%$ \\
\hline $\begin{array}{l}\text { S3 }(\log \\
\left.\text { cd. } \mathrm{m}^{-2} \cdot \mathrm{min}^{-1}\right)\end{array}$ & $0.04(0.02)$ & $0.05(0.02)$ & 0.05 & $0.34(0.05)$ & 0.05 & $40 \%$ \\
\hline $\mathrm{T}_{30}\left(\log \mathrm{cd} . \mathrm{m}^{-2}\right)$ & $-4.34(0.25)$ & $-4.40(0.44)$ & 0.63 & $0.84(<0.0001)$ & 0.35 & $10 \%$ \\
\hline
\end{tabular}

${ }^{\mathrm{a}}$ Independent $t$ test older vs. younger group 
Fig. 3 Test-retest differences versus means to assess the repeatability of dark adaptation curve parameters $S 2$ (panel a) and $T_{30}$ (panel b). The dotted line represents the bias (testretest mean differences) and the dashed lines represent $95 \%$ limits of agreement
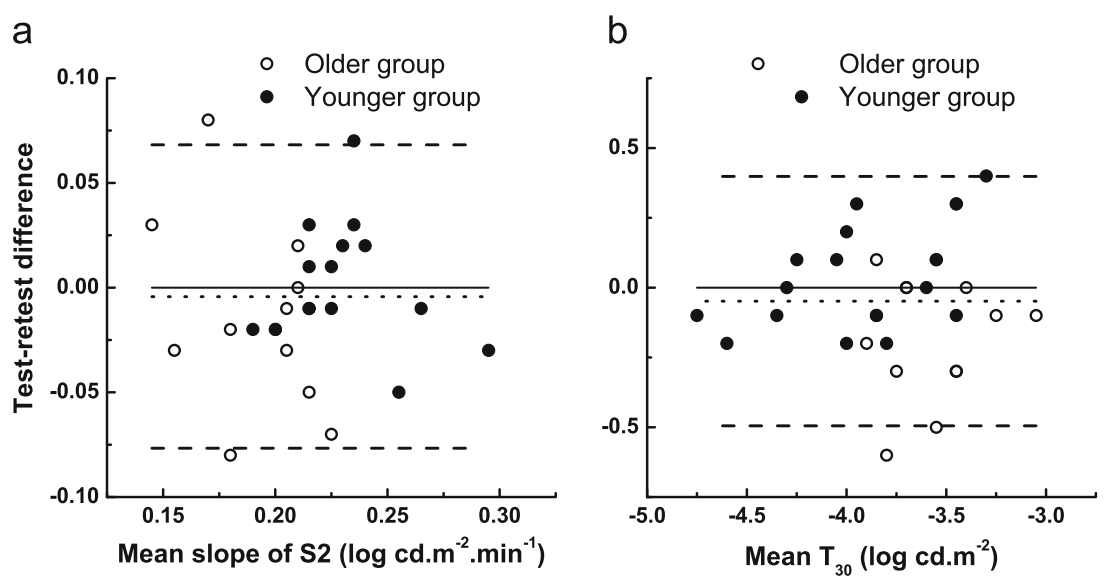

indicates threshold elevation across the entire roddominated region of sensitivity recovery.

A summary of statistical comparisons between the two groups for RCB, S2, S3, and $\mathrm{T}_{30}$ is presented in Table 1. The younger group had an average S2 of 0.23 $\pm 0.03 \mathrm{log}$ cd. $\mathrm{m}^{-2} \cdot \mathrm{min}^{-1}$, with a time constant $\left(\tau=\log _{10}\right.$ (e)/S2) of $1.9 \mathrm{~min}$. The older group was significantly slower than the younger group $(t=-4.05, p<0.0003)$, with an average S2 of $0.19 \pm 0.03 \log \mathrm{cd} \cdot \mathrm{m}^{-2} \cdot \mathrm{min}^{-1}$ $(\tau=2.3 \mathrm{~min})$. The negative correlation between $\mathrm{S} 2$ and age $(r=-0.62, p<0.0002)$ is shown in Fig. 5a. The rate of recovery over the S2 region decreased $0.01 \mathrm{log}$ units/min per decade. S2 was also correlated with $\mathrm{T}_{30}$ after corrections for media changes $(r=-0.49)$, as illustrated in Fig. 5b.

Before pre-retinal correction, $\mathrm{T}_{30}$ was elevated in the older group by $0.4 \log$ units $(t=3.14, p<0.004)$. However, after pre-retinal correction, the older group sustained a nonsignificant threshold elevation of $0.1 \mathrm{log}$ units compared with the younger group $(t=-0.48, p=0.63)$. We did not observe any significant gender differences for S2 $(t=0.28$, $p=0.79)$ and $\mathrm{T}_{30}(t=0.29, p=0.77)$ in our cohort. As shown in Table 1, there was no significant difference between the older and younger group for RCB $(t=0.23, p=0.82)$ and S3 $(t=-2.03, p=0.05)$.

\section{Discussion}

The data presented in this paper demonstrate that our CRTbased dark adaptometry produces results that agree with previous studies $[15,18]$. The slowing of component S2 with increasing age found in this study was $0.01 \mathrm{log}$ units/decade, and reflects reduced rhodopsin regeneration rate, in agreement with other psychophysical [14] and rod densitometry [28] data. The technique proved capable of differentiating between younger and older eyes (for the S2 parameter), despite no differences in VA and fundus appearance between the two groups. The power in this study to detect a difference between old and young eyes was 0.96 (calculated using G*Power 3.0.10). This is a good indicator of the ability of the technique to detect small changes in the slope of S2, either between two groups or in individuals in a longitudinal study.

Prolonged dark adaptation kinetics in older adults lead to difficulties with vision-oriented tasks in dim lighting, and increase the risk of night-time falls and road traffic accidents. These problems have been confirmed in selfreporting surveys such as that described by Scilley et al. [29], who used a questionnaire designed specifically for assessing low-light visual problems. Difficulties arise, however, in establishing the exact contribution of impaired night vision to accidents, because of the absence of a satisfactory
Fig. 4 Group data showing the $\mathrm{S} 2$ and $\mathrm{S} 3$ regions of rod recovery for younger (a) and older (b) subjects. A bilinear function was fitted to each data set. The younger group model (dashed line) is superimposed onto the older group data in $\mathbf{b}$ to demonstrate slowing of the S2 region and elevated thresholds in the older group. Data have been shifted along the $x$ and $y$ axes so that the individual RCBs were coincident a

है

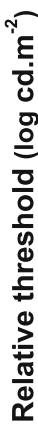

b

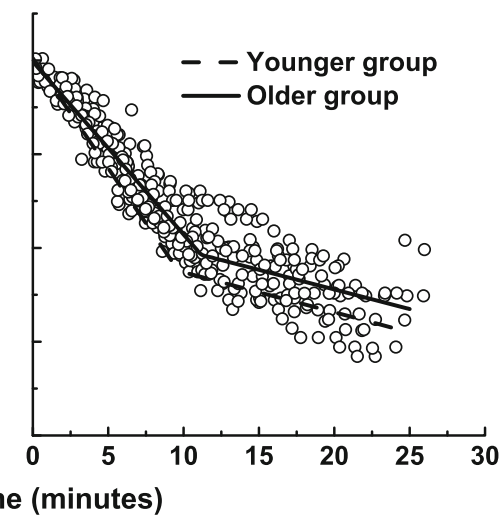


Fig. 5 a Scatter plot of S2 as a function of age. The line represents linear regression fitted to the data $(r=-0.62, p<$ $0.0002)$. b Scatter plot with a line of best fit illustrating negative correlation between $T_{30}$ and $S 2(r=-0.49)$. All data points are means of two sessions. Thresholds were corrected for lens density and pupil miosis

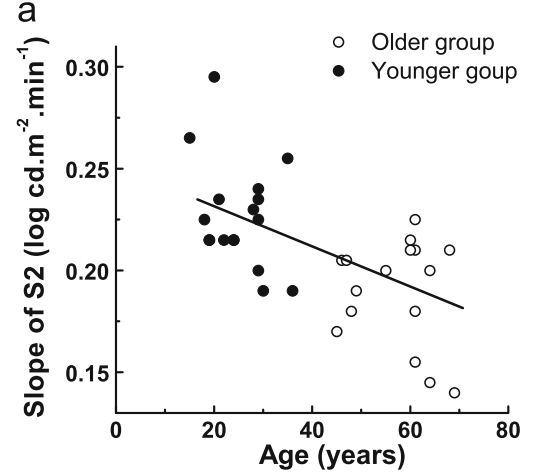

test which can be used routinely under clinical conditions. It seems likely that those older observers with a healthy lifestyle and good nutrition can be expected to have relatively good scotopic recovery, but confirming such a hypothesis might be difficult, because a technique for measuring the slope of S2 precisely is not generally available. The method described here could be used to quantitatively assess patient night vision with excellent reproducibility, enabling researchers to use scotopic recovery as a realistic outcome measure.

The correlation we found between the rate of rodmediated recovery (slope of $\mathrm{S} 2$ ) and $\mathrm{T}_{30}$ is at odds with one previous study [30]. In that previous study, the absolute threshold was measured which may not be directly comparable to our measure of threshold after $30 \mathrm{~min}$. Our correlation can be explained by geometry of the dark adaptation function and by the cellular model of recovery kinetics presented by Lamb and Pugh [15]. If the slope of S2 is steeper, then the threshold at $30 \mathrm{~min}$ will be lower. Although the measurements were restricted to $30 \mathrm{~min}$, and some observers would have reached lower thresholds had the time been extended, it seems likely that the rate of $\mathrm{S} 2$ and $\mathrm{T}_{30}$ share the same cellular and molecular mechanisms [15].

The CRT method has previously been compared with the conventional Goldmann-Weekers adaptometer (GWA), showing good agreement between the two methods on almost all parameters of the dark adaptation curve including cone recovery rate, $\mathrm{RCB}$ and S2 [18]. The general problem with the GWA is its poor repeatability for cone recovery. Gaffney et al. [31] have shown a clinically unacceptable CoR for cone recovery time constant, and concluded that the GWA would not be a useful instrument for documenting visual changes in future clinical trials. Christoforidis and Zhang [32] also used GWA in a test-retest paradigm. They showed no learning effects and no statistically significant differences on repeated measures for any of the parameters of the scotopic recovery curve. Although their group mean S2 recovery rate of $0.15 \mathrm{log}$ cd. $\mathrm{m}^{-2} \cdot \mathrm{min}^{-1}$ is slower than ours and that typically reported in the literature for healthy subjects, their CoR for S2 of $0.06 \log$ cd. $\mathrm{m}^{-2} \cdot \mathrm{min}^{-1}$ is very similar to ours.

Dimitrov et al. [18] used a similar method to the one described in this article. However, in that study, which also investigated $\mathrm{AMD}$ patients, the $\mathrm{CoV}$ for the rod parameters was not given. Their CoV for the RCB was $32 \%$ for normal and $44 \%$ for AMD subjects, which is slightly higher than our COV of $28 \%$. Of note is the considerably larger COV for $\mathrm{RCB}$ and $\mathrm{S} 3$ than for $\mathrm{S} 2$ and $\mathrm{T}_{30}$ in the present study. This could be due to the fact that, unlike S2, the RCB and S3 are largely dependent on the magnitude of the bleach [15], which highlights the importance of precise and uniform bleaching between visits for longitudinal clinical trials. In the present study, we were able to accurately bleach the area to be tested by using a semi-silvered mirror. Although we did not dilate the pupils because we were primarily interested in the slope of S2 (and used bleaches $\geq 30 \%$ ), we would highly recommend pupil dilation in future clinical trials investigating multiple dark adaptation parameters. This is because dilation of pupils allows tighter control over the bleach.

Finally, our technique readily elicited the third rod component (S3) unlike the protocol suggested by Dimitrov et al. [18] using a single $2.6 \log$ unit ND filter. Such a narrow range may pose problems in evaluating dark adaptation in ageing, particularly in subjects with good scotopic sensitivity due to its ceiling effect.

In summary, the results of this study demonstrate the validity of using an easily implemented computer-based technique to explore scotopic sensitivity recovery in ageing, using an automated and inexpensive method of expanding the luminance range with ND filters. The method is highly repeatable for the measurement of rod-mediated dark adaptation parameters ( $\mathrm{S} 2$ and $\mathrm{T}_{30}$ ), without requiring pupil dilation. Because of its sound physiological basis, S2 is of particular interest. It seems likely that given its many advantages, dark adaptometry based on digital methods will become the method of choice for future work in assessing retinal health in the older eye with and without ocular pathology.

Acknowledgments Supported by BBSRC grant (BB/F017227/1) and Vitabiotics. NRAP and TA's involvement was facilitated by the Manchester Biomedical Research Centre and the Greater Manchester Comprehensive Local Research Network. DHB was supported by EPSRC grant (EP/H000038/1).

NRAP has a proprietorial interest in the software described here. 
Open Access This article is distributed under the terms of the Creative Commons Attribution License which permits any use, distribution, and reproduction in any medium, provided the original author(s) and the source are credited.

\section{References}

1. Russell RM, Multack R, Smith VC, Krill A, Rosenberg IH (1973) Dark-adaptation testing for diagnosis of subclinical vitamin-A deficiency and evaluation of therapy. Lancet 302(7839):1161-1164

2. Abbott-Johnson WJ, Kerlin P, Abiad G, Clague AE, Cuneo RC (2010) Dark adaptation in vitamin A-deficient adults awaiting liver transplantation: improvement with intramuscular vitamin A treatment. Br J Ophthalmol 95(4):544-548

3. Henson DB, North RV (1979) Dark adaptation in diabetes mellitus. Br J Ophthalmol 63(8):539-541

4. Phipps JA (2006) Rod photoreceptor dysfunction in diabetes: activation, deactivation, and dark adaptation. Invest Ophthalmol Vis Sci 47(7):3187-3194

5. Brown B, Adams AJ, Coletta NJ, Haegerstrom-Portnoy G (1986) Dark adaptation in age-related maculopathy. Ophthalmic Physiol Opt 6(1):81-84

6. Steinmetz R, Haimovici R, Jubb C, Fitzke FW, Bird AC (1993) Symptomatic abnormalities of dark adaptation in patients with agerelated Bruch's membrane change. Br J Ophthalmol 77(9):549-554

7. Owsley C, McGwin G, Jackson G, Kallies K, Clark M (2007) Cone- and rod-mediated dark adaptation impairment in age-related maculopathy. Ophthalmology 114(9):1728-1735

8. Owsley C, Jackson GR, White M, Feist R, Edwards D (2001) Delays in rod-mediated dark adaptation in early age-related maculopathy. Ophthalmology 108(7):1196-1202

9. Owsley C, Jackson GR, Cideciyan AV, Huang Y, Fine SL, Ho AC, Maguire MG, Lolley V, Jacobson SG (2000) Psychophysical evidence for rod vulnerability in age-related macular degeneration. Invest Ophthalmol Vis Sci 41(1):267

10. Jackson G, Aleman TS, Owsley C (2006) The scotopic sensitivity tester- 1 and the detection of early age-related macular degeneration. Ophthalmic Physiol Opt 26(4):431-437

11. Omar R, Herse P (2004) Quantification of dark adaptation dynamics in retinitis pigmentosa using non-linear regression analysis. Clin Exp Optom 87(6):386-389

12. Ruether K, Apfelstedt-Sylla E, Zrenner E (1993) Clinical findings in patients with congenital stationary night blindness of the Schubert-Bornschein type. Ger J Ophthalmol 2(6):429-435

13. Coile DC, Baker HD (1992) Foveal dark adaptation, photopigment regeneration, and aging. Vis Neurosci 8(1):27-39

14. Jackson GR, Owsley C, McGwin G Jr (1999) Aging and dark adaptation. Vis Res 39(23):3975-3982
15. Lamb TD, Pugh EN (2006) Phototransduction, dark adaptation, and rhodopsin regeneration the proctor lecture. Invest Ophthalmol Vis Sci 47(12):5138

16. Lamb TD (1981) The involvement of rod photoreceptors in dark adaptation. Vis Res 21(12):1773-1782

17. Curcio CA, Owsley C, Jackson GR (2000) Spare the rods, save the cones in aging and age-related maculopathy. Invest Ophthalmol Vis Sci 41(8):2015

18. Dimitrov PN, Guymer RH, Zele AJ, Anderson AJ, Vingrys AJ (2008) Measuring rod and cone dynamics in age-related maculopathy. Invest Ophthalmol Vis Sci 49(1):55

19. Dimitrov PN, Robman LD, Varsamidis M, Aung KZ, Makeyeva GA, Guymer RH, Vingrys AJ (2011) Visual function tests as potential biomarkers in age-related macular degeneration. Invest Ophthalmol Vis Sci 52(13):9457-9469

20. Bland JM, Altman DG (1986) Statistical methods for assessing agreement between two methods of clinical measurement. Lancet 1(8476):307-310

21. Jackson GR, Owsley C, Curcio CA (2002) Photoreceptor degeneration and dysfunction in aging and age-related maculopathy. Ageing Res Rev 1(3):381-396

22. Rushton WAH, Powell DS (1972) The rhodopsin content and the visual threshold of human rods. Vis Res 12(6):10731081

23. McGwin G, Jackson GR, Owsley C (1999) Using nonlinear regression to estimate parameters of dark adaptation. Behav Res Methods Instrum Comput J Psychon Soc Inc 31(4):712-717

24. Birren JE, Shock NW (1950) Age changes in rate and level of visual dark adaptation. J Appl Physiol 2(7):407-411

25. Pulos E (1989) Changes in rod sensitivity through adulthood. Invest Ophthalmol Vis Sci 30(8):1738-1742

26. Sturr JF, Zhang L, Taub HA, Hannon DJ, Jackowski MM (1997) Psychophysical evidence for losses in rod sensitivity in the aging visual system. Vis Res 37(4):475-481

27. Pokorny J, Smith VC, Lutze M (1987) Aging of the human lens. Appl Opt 26(8):1437

28. Liem AT, Keunen JE, Van Norren D, Van de Kraats J (1991) Rod densitometry in the aging human eye. Invest Ophthalmol Vis Sci 32(10): 2676

29. Scilley K, Jackson GR, Cideciyan AV, Maguire MG, Jacobson SG, Owsley C (2002) Early age-related maculopathy and selfreported visual difficulty in daily life. Ophthalmology 109(7):1235-1242

30. Jackson GR, Owsley C (2000) Scotopic sensitivity during adulthood. Vis Res 40(18):2467-2473

31. Gaffney AJ, Binns AM, Margrain TH (2011) The repeatability of the Goldmann-Weekers adaptometer for measuring cone adaptation. Doc Ophthalmol 122(2):71-75

32. Christoforidis J, Zhang X (2011) Learning effect of dark adaptation among normal subjects. Graefes Arch Clin Exp Ophthalmol 249(9):1345-1352 